\title{
Hepatites virais na gestação e a importância do pré-natal
}

\author{
Viral hepatitis in pregnancy and the importance of prenatal care
}

Hepatitis virales en el embarazo y la importancia del control prenatal

Letícia Maia Zica $^{1 *}$, Ana Carolina Souza Sisnando de Araujo ${ }^{1}$, Ana Luisa Jaramillo Garcia ${ }^{1}$, Beatriz da Costa Luiz Bonelly ${ }^{1}$, Bruna Paiva de França ${ }^{1}$, Fabiana Pilotto Muniz Costa Leal ${ }^{1}$, Giovanna Abe Rodrigues de Melo ${ }^{1}$, Isabella Nascentes Tanizaki Coelho ${ }^{1}$, Kamila Catta Preta Carneiro de Sousa ${ }^{1}$, Maria Clara Ibrahim Saraiva'.

\section{RESUMO}

Objetivo: Descrever achados da literatura atual sobre hepatites virais na gestação e a importância do prénatal para melhores desfechos. Revisão bibliográfica: As hepatites virais apresentam alta prevalência no Brasil e no mundo, com grande impacto social, sendo que alguns agentes etiológicos possuem capacidade de transmissão materno-fetal. Portanto, há uma necessidade de estabelecer o perfil epidemiológico de gestantes para um rastreio, diagnóstico e manejo precoces. Além disso, a gestação é um momento oportuno para a gestante ter contato com a Atenção Básica para a realização do pré-natal adequado, incluindo testagem para hepatites e demais sorologias necessárias. Considerações finais: a possibilidade de acesso ao pré-natal em Unidades Básicas de Saúde é um dos principais instrumentos para a redução e identificação precoce dos casos de hepatites virais e suas complicações. A possibilidade de acesso a testes sorológicos, vacinas e terapias profiláticas garantem melhores desfechos e qualidade de vida para a gestante, feto e neonato.

Palavras-chave: Hepatite viral humana, Gestantes, Atenção primária à saúde, Transmissão vertical de doença infecciosa, Cuidado pré-natal.

\begin{abstract}
Objective: To describe the findings from the current literature on viral hepatitis in pregnancy and the importance of prenatal care for better outcomes. Bibliographic review: Viral hepatitis are highly prevalent in Brazil and worldwide, having a great social impact, and some etiologic agents have the capacity for maternalfetal transmission. Therefore, it is needed to establish the epidemiological profile of pregnant women for early screening, diagnosis and management. In addition, pregnancy is an appropriate time for contacting and bonding with Primary Care and the establishment of adequate prenatal care, including testing for hepatitis and other necessary serologies. Final considerations: The possibility of access to prenatal care in Basic Health Units is one of the main tools for the reduction and early identification of cases of viral hepatitis and its complications. Getting access to serological tests, vaccines and prophylactic therapies guarantee better outcomes and a higher quality of life for mother, fetus and newborn.
\end{abstract}

Keywords: Human viral hepatitis, Pregnant women, Primary health care, Viral infectious disease transmission, Prenatal care.

\section{RESUMEN}

Objetivo: Describir los hallazgos de la literatura actual sobre la hepatitis viral durante el embarazo y sobre la importancia de la atención prenatal para obtener mejores resultados. Revisión bibliográfica: La hepatitis viral es altamente prevalente en Brasil y en el mundo, con gran impacto social y algunos de los agentes etiológicos tienen capacidad de transmisión materno-fetal. Por tanto, es necesario establecer el perfil epidemiológico de la gestante para su detección, diagnóstico y manejo precoces. Además, el embarazo es un momento oportuno para el contacto con la Atención Primaria y para la realización de una atención prenatal adecuada, incluidas las pruebas de hepatitis y otras serologías necesarias. Consideraciones finales: La posibilidad de acceder a la atención prenatal en Unidades Básicas de Salud es uno de los principales instrumentos de reducción e identificación temprana de los casos de hepatitis viral y también de sus

${ }^{1}$ Centro Universitário de Brasília (UniCEUB), Brasília - DF. *E-mail: leticiamzica2@gmail.com 
complicaciones. La posibilidad de acceso a pruebas serológicas, vacunas y terapias profilácticas garantizan mejores resultados y mejor calidad de vida de las embarazadas, fetos y recién nacidos.

Palabras clave: Hepatitis viral humana, Mujeres embarazadas, Atención primaria de salud, Transmisión vertical de enfermedad infecciosa, Atención prenatal.

\section{INTRODUÇÃO}

As doenças infecciosas na gestação podem acontecer por diversos patógenos e possuem potencial para aumento da morbimortalidade perinatal. Portanto, há uma necessidade do diagnóstico precoce dessas patologias durante as consultas de pré-natal (BRASIL, 2012).

É preconizado pelo Ministério da Saúde (MS) (2012) a solicitação de sorologias - sífilis, toxoplasmose, rubéola, HIV e a hepatite B - desde a primeira consulta. Alguns autores recomendam a testagem também para hepatite $C$ e hepatite $E$ em situações específicas.

As hepatites virais são um grupo de doenças causadas por agentes com tropismo por hepatócitos. Os principais agentes etiológicos são os vírus da Hepatite A (HAV), Hepatite B (HBV), Hepatite C (HCV), Hepatite D (HDV) e Hepatite E (HEV). Dentre esses, o HBV, HCV e o HEV ganham destaque na gestação devido a possibilidade de transmissão materno-fetal (BRASIL, 2015).

As hepatites $B$ e $C$ no Brasil não possuem uma prevalência homogênea, havendo divergências entre regiões, cobertura vacinal e migração. No entanto, estima-se que haja 1,5 milhão de infectados pelo HCV e até $1 \%$ da população pelo HBV (BARROS MMO, et al., 2018).

A transmissão vertical é o principal meio do VHB persistir na população, pois a infecção crônica ocorre em até $90 \%$ das crianças que possuem mães com exames positivos durante seu nascimento. Essa porcentagem é importante pois, quando analisados estudos com a população geral, esse risco cai de $90 \%$ para 5 a $10 \%$, ressaltando a necessidade de medidas para diminuição da transmissão vertical (FERNANDES CNS, et al., 2014).

A transmissão em gestantes infectadas pode ocorrer na gestação ou durante e após o parto. O HCV possui menor taxa de transmissão quando comparado com o HBV, entretanto, aumenta em casos de mães com coinfecções, como o HIV, ou com cargas virais elevadas (FERNANDES CNS, et al., 2014).

Alguns exames podem ser utilizados para realizar o diagnóstico e oferecer um prognóstico de acordo com a evolução da doença. Exames laboratoriais gerais caracterizam o estado do fígado, como os índices das enzimas hepáticas alanina aminotransferase (ALT/TGP) e aspartato aminotransferase (AST/TGO), que aumentam sensivelmente ao surgimento dos sintomas iniciais. Ademais, há paralelamente um aumento nos níveis das bilirrubinas e possíveis alterações nos fatores de coagulação. Outra opção relacionada ao diagnóstico das hepatites virais é a biópsia hepática, porém não recomendada durante a gestação (PIAZZA MJ, et al., 2010).

Quanto a exames laboratoriais específicos, é necessário pontuar que sorologias específicas para cada antígeno viral são de natureza determinante para o diagnóstico correto e melhor prognóstico para a gestante. Essa identificação dos antígenos e seus respectivos anticorpos irá variar de acordo com o tipo da hepatite viral a ser pesquisado (PIAZZA MJ, et al., 2010).

O diagnóstico e o tratamento precoce dessa, e de outras patologias, podem impactar positivamente a vida da gestante e do recém-nascido (RN), portanto, um pré-natal de qualidade é fundamental. Embora tenha aumentado sua cobertura no país, é visível que a qualidade dessa atenção ainda precisa de melhorias. Algumas das falhas são principalmente relacionadas a grupos populacionais menos favorecidos socioeconomicamente, que possuem dificuldade de acesso, com início tardio, menos consultas e realização incompleta de procedimentos (VIELLAS EF, et al., 2014).

O objetivo deste estudo é descrever a literatura recente sobre hepatites virais na gestação e o impacto do pré-natal em desfechos mais favoráveis para mãe e recém-nascido, demonstrando a importância do acompanhamento inicial de gestantes portadoras ou não de hepatites a fim de realizar um diagnóstico e tratamento precoce daquelas acometidas pela infecção. 


\section{REVISÃO BIBLIOGRÁFICA}

\section{Epidemiologia}

Diante do alto risco de transmissão vertical do vírus da hepatite, torna-se importante traçar o perfil epidemiológico das gestantes, uma vez que práticas de detecção contribuem para identificar pacientes infectadas e reduzir o impacto e a disseminação do vírus (SETO MT, et al., 2020).

A infecção pelo HAV é considerada a causa mais comum de hepatite viral aguda. Entretanto, durante o período gestacional, tem baixa incidência. O HAV é disseminado, principalmente, por via fecal-oral, através de água e alimentos contaminados e também por meio do sexo oral-anal. Por esse motivo, a infecção por HAV é mais elevada em países de baixa renda, devido às más condições sanitárias (SETO MT, et al., 2020). No Brasil, a HAV ocorre majoritariamente na primeira infância de modo agudo, não levando a infecção crônica. Além disso, a transmissão perinatal dessa hepatite é rara (PESSOA MG e MORAES A, 2018).

O HBV é considerado o principal agente causador de hepatite crônica no mundo. No Brasil, apesar de existirem áreas específicas com alta prevalência (Amazônia, Paraná e Santa Catarina), sua prevalência nacional é baixa (BRASIL, 2016). De acordo com dados do MS, pelo menos $15 \%$ da população brasileira já esteve em contato com o vírus da hepatite $B$ e $1 \%$ apresenta doença crônica relacionada ao HBV (FERREIRA CT e SILVEIRA TR, 2004). A infecção crônica pode evoluir para insuficiência hepática, cirrose e carcinoma hepatocelular, sendo estas as principais causas de morte por hepatite B (CHILAKA VN e KONJE JC, 2020).

A hepatite $C$ também é uma das principais causas de hepatite crônica, cirrose e carcinoma hepatocelular no mundo. No Brasil, $1,38 \%$ da população tem anti-HCV positivo, e aproximadamente $70 \%$ desses têm infecção ativa (HCV RNA detectado) (PESSOA MG e MORAES A, 2018). Segundo estimativa da Organização Mundial de Saúde (OMS), 1\% da população mundial vivia com o HCV em 2015, sendo mais prevalente na população grávida. Na triagem pré-natal, o uso de drogas injetáveis, procedimentos de saúde inseguros, histórico de transfusão sanguínea ou derivados, hemodiálise e portadores de piercings ou tatuagens são os principais fatores de risco e vias de transmissão do vírus (CHILAKA VN e KONJE JC, 2020).

O HDV requer coinfecção por HBV para sua transmissão e replicação. Ressalta-se ainda a definição de superinfecção, em que há infecção pelo HDV em paciente portador crônico do HBV (BRASIL, 2008). A subnotificação dos casos impossibilita a obtenção minuciosa de dados, entretanto, a OMS estima que 15-20 milhões de pessoas estejam infectadas em todo o mundo (SETO MT, et al., 2020). Segundo estudo, a prevalência de HDV pode ser de até 14,7\% (16/109) em gestantes portadoras de HBV (MANSOUR W, et al., 2012).

A hepatite E é uma das principais causas de hepatite aguda no mundo. O HEV é transmitido via zoonótica, água contaminada e alimentos infectados mal cozidos ou via fecal-oral (SETO MT, et al., 2020). Assim como o HAV, é endêmica em países em desenvolvimento, devido à falta de saneamento básico. Dados epidemiológicos mostram que o HEV apresenta maior prevalência e é mais virulento durante o ciclo gravídico, uma vez que possui uma maior taxa de insuficiência hepática fatal do que os outros agentes conhecidos de hepatite viral (PÉREZ-GRACIA MT, et al., 2017). Mais de 75\% dos casos de gestantes que desenvolvem hepatite fulminante, em áreas endêmicas, estão relacionados à infecção por HEV (SETO MT, et al., 2020). Estima-se que a infecção por HEV seja responsável por cerca de 2.400 a 3.000 natimortos a cada ano (PÉREZ-GRACIA MT, et al., 2017).

\section{Transmissão Vertical}

A transmissão vertical do HAV não é considerada uma causa comum de hepatite neonatal (SETO MT, et al., 2020). Já na hepatite $B$, a transmissão acontece comumente no momento do parto, mas também pode ocorrer por via transplacentária, quando há ruptura da barreira materno-fetal (CHILAKA VN e KONJE JC, 2020). O maior risco está associado à positividade do $\mathrm{HBeAg}$, marcador que indica replicação viral e aumenta o risco em até $80 \%$ (CONCEIÇÃO JS, et al., 2009).

Na hepatite C, o maior número de casos de transmissão da mãe para o filho também acontece no parto, entretanto, o risco de transmissão com pacientes infectadas com o HCV é menor do que com o HBV (PESSOA 
MG e MORAES A, 2018; BARROS MM, et al., 2018). Um estudo realizado em 2004 constatou a presença de uma viremia mais alta nos casos em que a transmissão acontece, contudo, o mesmo afirma não existir consenso na literatura para corroborar este achado (PEIXOTO MF, et al., 2004).

$A$ transmissão materno-fetal da hepatite $D$ é possível, mas é considerada rara e está relacionada à carga viral de HBV (SETO MT, et al., 2020). Já a transmissão vertical da hepatite E é comum e acontece pela via intra uterina ou perinatal, estando associada ao aumento da mortalidade fetal e neonatal (PESSOA MG e MORAES A, 2018).

\section{Quadro Clínico}

Como citado anteriormente, a infecção pelo VHA durante a gestação é rara e, em sua maioria, não causa grandes complicações em regiões mais desenvolvidas. Assim, o parto das gestantes portadoras ocorre, em média, com 34 semanas, porém, se apresentarem febre e hipoalbuminemia, o parto precisa ser realizado com 32 semanas (PESSOA MG e MORAES A, 2018).

No que se refere à hepatite $B$, há ocorrência da forma aguda e crônica, sendo o curso da doença semelhante ao da população em geral, com apenas $50 \%$ dos infectados sintomáticos e com a possibilidade de hepatite fulminante de apenas $1 \%$ na infecção aguda. Ademais, neonatos filhos de mães positivas no momento do parto possuem quase $90 \%$ de chance de adquirir infecção crônica (ŁAPIńSKI TW, et al., 2015).

Já nas grávidas com superinfecção HBV/HDV, não há especificação na literatura de piora no desfecho clínico associada à coinfecção na gestação (SETO MT, et al., 2020).

A respeito da hepatite $C$, foi observado maior ocorrência de diabetes e hipertensão gestacionais. Há também maior risco de parto prematuro e de anomalias congênitas nos fetos de mães com HCV positivo (PESSOA MG e MORAES A, 2018).

No início da infecção pelo VHE não há significativas diferenças entre os sintomas de mulheres grávidas e não grávidas. Porém, em um curto período de tempo, nas grávidas, a infecção pode levar a falência hepática aguda, levando à ocorrência de coagulação intravascular disseminada, encefalopatia e edema cerebral, que pode afetar até $70 \%$ das grávidas com VHE. A complicação mais comum dessa hepatite é o coma hepático, podendo levar à morte quase todas as gestantes/mulheres acometidas. A depender da carga viral e da severidade dos sintomas, o óbito pode ocorrer tanto no feto quanto na mãe, em maior número no terceiro trimestre (PÉREZ-GRACIA MT, et al., 2017).

\section{Diagnóstico}

Exames Sorológicos: O diagnóstico das hepatites virais é confirmado a partir da detecção de anticorpos específicos da classe lgM e marcadores correspondentes a cada tipo viral, já infecções passadas, pela classe IgG. As respectivas interpretações dos resultados sorológicos e marcadores encontram-se abaixo (Quadros 1, 2, 3, 4 e 5) (BRASIL, 2008).

Quadro 1 - Interpretação de Resultados Sorológicos para Hepatite A.

\begin{tabular}{|c|c|l|}
\hline Anti-HAV Total & Anti-HAV IgM & \multicolumn{1}{|c|}{ Interpretação } \\
\hline$(+)$ & $(+)$ & Infecção recente pelo vírus da hepatite A. \\
\hline$(+)$ & $(-)$ & Infecção passada pelo vírus da hepatite A ou imunizado pela vacina. \\
\hline$(-)$ & $(-)$ & Ausência de contato com o vírus da hepatite A, não imune (suscetível). \\
\hline
\end{tabular}

Fonte: Zica LM, et al., 2021; dados extraídos do Ministério da Saúde (2008). 
Quadro 2 - Interpretação dos Marcadores e Resultados Sorológicos para Hepatite B.

\begin{tabular}{|c|c|c|c|c|c|c|}
\hline Marcador & \multicolumn{6}{|c|}{ Interpretação } \\
\hline HBsAg & \multicolumn{6}{|c|}{$\begin{array}{l}\text { Primeiro marcador a surgir no curso da infecção pelo HBV. } \\
\text { Hepatite aguda: declina a níveis indetectáveis em até } 24 \text { semanas. } \\
\text { Hepatite crônica: indicativo quando presente por mais de } 24 \text { semanas. }\end{array}$} \\
\hline Anti-HBc IgM & \multicolumn{6}{|c|}{ Marcador de infecção recente. Encontrado até 32 semanas após infecção. } \\
\hline Anti-HBc lgG & \multicolumn{6}{|c|}{ Marcador de longa duração. Representa contato prévio com o vírus. } \\
\hline $\mathrm{HBeAg}$ & \multicolumn{6}{|c|}{$\begin{array}{l}\text { Marcador de replicação viral. Indicativo de alta infecciosidade. } \\
\text { Hepatite crônica: presente enquanto ocorrer replicação viral. }\end{array}$} \\
\hline Anti-HBe & \multicolumn{6}{|c|}{ Aparece após o desaparecimento do HBeAg. Indica o fim da fase replicativa. } \\
\hline Anti-HBs & \multicolumn{6}{|c|}{$\begin{array}{c}\text { Único anticorpo que confere imunidade ao HBV. Indicador de cura e imunidade. } \\
\text { Presente isoladamente em pessoas vacinadas. }\end{array}$} \\
\hline Interpretação & HBsAg & HBeAg & Anti-HBc IgM & Anti-HBc IgG & Anti-HBe & Anti-HBs \\
\hline Susceptível & $(-)$ & $(-)$ & $(-)$ & $(-)$ & $(-)$ & $(-)$ \\
\hline Incubação & $(+)$ & $(-)$ & $(-)$ & $(-)$ & $(-)$ & $(-)$ \\
\hline Fase Aguda & $(+)$ & $(+)$ & $(+)$ & $(+)$ & $(-)$ & $(-)$ \\
\hline $\begin{array}{l}\text { Imunidade } \\
\text { Recente }\end{array}$ & $(-)$ & $(-)$ & $(-)$ & $(+)$ & $(+)$ & $(+)$ \\
\hline $\begin{array}{l}\text { Infecção } \\
\text { Passada }\end{array}$ & $(-)$ & $(-)$ & $(-)$ & $(+)$ & $(-)$ & $(+)$ \\
\hline $\begin{array}{l}\text { Resposta } \\
\text { Vacinal }\end{array}$ & $(-)$ & $(-)$ & $(-)$ & $(-)$ & $(-)$ & $(+)$ \\
\hline
\end{tabular}

Fonte: Zica LM, et al., 2021; dados extraídos do Ministério da Saúde (2008).

Quadro 3 - Interpretação dos Marcadores para Hepatite C.

\begin{tabular}{|c|c|}
\hline Marcador & Interpretação \\
\hline Anti-HCV & $\begin{array}{r}\text { Marcador de contato prévio com o HCV. Não há definição de infecção recente, tardia, } \\
\text { pregressa e curada, ou, ainda, se houve cronificação. Para confirmação de infeçãa aguda, é } \\
\text { necessário uma viragem sorológica documentada. }\end{array}$ \\
\hline
\end{tabular}

Fonte: Zica LM, et al., 2021; dados extraídos do Ministério da Saúde (2008). 
Quadro 4 - Interpretação dos Marcadores e Resultados Sorológicos para Hepatite D.

\begin{tabular}{|c|c|c|c|c|c|}
\hline Marcador & \multicolumn{5}{|c|}{ Interpretação } \\
\hline HDVAg & \multicolumn{2}{|c|}{ Indica infecção aguda pelo HDV. Existe controvérsia entre os autores sobre esse } \\
marcador.
\end{tabular}

Fonte: Zica LM, et al., 2021; dados extraídos do Ministério da Saúde (2008).

Quadro 5 - Interpretação de Resultados Sorológicos para Hepatite E.

\begin{tabular}{|c|c|c|}
\hline Anti-HEV Total & Anti-HEV IgM & Interpretação \\
\hline$(+) /(-)$ & $(+)$ & Infecção recente pelo vírus da hepatite E. \\
\hline$(+)$ & $(-)$ & Exposição prévia pelo vírus da hepatite E. \\
\hline$(-)$ & $(-)$ & Ausência de contato com o vírus da hepatite A, não imune (suscetível). \\
\hline
\end{tabular}

Fonte: Zica LM, et al., 2021; dados extraídos do Ministério da Saúde (2008).

Exames de Biologia Molecular: Um segundo método de diagnóstico é através de exames moleculares que determinam a carga viral por análises de DNA e RNA virais. É utilizado para determinar atividade do vírus, definir necessidade de tratamento e potencial de transmissibilidade (BRASIL, 2016).

$O$ vírus da hepatite $B$ é analisado em exames sorológicos através de HBV DNA. O aumento deste marcador pode indicar necessidade terapêutica prolongada e tratamento no terceiro trimestre de gestação para diminuir as chances de transmissão para o feto. Quando há níveis de HBV DNA menores que $10^{8}$ cópias/ml não há relatos de transmissão vertical do HBV, de acordo com o Guia Prático: Infecções no Ciclo Grávido-Puerperal da Febrasgo (2016). 
Para a realização de um diagnóstico de transmissão materno-infantil, realiza-se a pesquisa de anti-HCV e HCV RNA no RN com 15 a 18 meses de idade em duas análises com intervalo de pelo menos três meses. Como a detecção do HCV RNA está relacionada à infecção ativa, a prevalência da transmissão vertical quando a mãe tem esse marcador é maior quando comparada à positividade do anti-HCV (FEBRASGO, 2016).

Em relação a hepatite E, o diagnóstico é feito com a presença do HEV RNA em exames moleculares, após positivação dos testes rápidos, permitindo sua detecção desde o período de incubação, até 21 dias após os sintomas, mesmo com variação da carga viral (PÉREZ-GRACIA MT, et al., 2017).

A presença de carga viral elevada indica maior probabilidade de transmissão vertical, portanto, o manejo com o RN será com vacina e imunoglobulinas (MACHADO FILHO AC, et al., 2010).

Testes de Função Hepática: Nos quadros de hepatite B na gravidez, os testes de função hepática são importantes para investigar lesão hepática e determinar um manejo individualizado. No caso da presença de cirrose, fibrose avançada ou ALT elevada durante a gestação, recomenda-se tratamento precoce. Para aquelas que não possuem nenhum desses critérios, a necessidade da terapêutica deve ser discutida e possivelmente adiada. Os testes de função hepática devem ser associados com exames de biologia molecular, pois a presença de HBV DNA elevado está relacionada com a necessidade de tratamento no terceiro trimestre para reduzir a possibilidade de transmissão vertical (PESSOA MG e MORAES A, 2018).

Os níveis de ALT e de AST são utilizados para indicar lesão hepática e começam a se elevar desde do período prodrômico. O aumento de ALT de 2 a 100 vezes o valor de referência, sugere infecção ativa e em progressão, podendo diminuir quando a cirrose se estabelece (CHILAKA VN e KONJE JC, 2020).

\section{Imunização}

A imunização em gestantes busca proteção e prevenção da transmissão de diversas doenças para mãe e RN. Entretanto, sabe-se que a saúde de cada mulher é diferente em suas gestações e, apesar de diretrizes básicas existirem, cabe aos profissionais de saúde determinarem a melhor estratégia para imunização. São levados em consideração vacinações anteriores, gestação de alto ou moderado risco, histórico patológico e comorbidades associadas (TAVARES MV, et al., 2011).

Assim como em qualquer situação, a vacinação na gravidez possui riscos, só devendo ocorrer quando esses forem superados pelos benefícios da imunização. A vacina contra HAV é constituída por vírus inativado e deve ser administrada se a gestante apresentar risco de exposição ao agente (TAVARES MV, et al., 2011). Já a vacina contra HBV possui 3 doses, sendo recomendada a aplicação com intervalo de 30 dias entre a primeira e a segunda dose e 6 meses entre a primeira e a terceira doses (BRASIL, 2014). Essa vacina não possui contraindicação específica para gestantes e é administrada de acordo com o esquema vacinal da mulher, fornecendo as doses restantes.

A imunização contra HBV, de RN de mães portadoras da doença, deve ser feita preferencialmente nas primeiras 12 horas pós-parto e, até no máximo, 7 dias de vida do RN. Essa administração precoce, com vacina e imunoglobulina proporciona melhor defesa e eficácia dos métodos de imunização, conferindo maior segurança para a criança (MACHADO FILHO AC, et al., 2010).

\section{Impacto Social}

Segundo a OMS (2017), cerca de 325 milhões de pessoas possuem infecção crônica pelo HBV ou HCV. Em 2015 as hepatites virais causaram 1,34 milhão de mortes, um número maior do que as mortes causadas por HIV no mesmo ano. Dessa forma, as autoras concordam que o impacto social das hepatites virais não se limita apenas ao número elevado de casos no país e no mundo, que exige direcionamento de recursos diagnósticos e terapêuticos, mas também na quantidade de complicações que podem ocorrer a longo prazo.

De 2013 a 2017 foram registradas 4.317 internações para o tratamento de hepatites virais no Nordeste brasileiro com altos custos para o governo principalmente devido à cirrose hepática, que exige mais gastos com recursos terapêuticos (SOUZA JÚNIOR EV, et al., 2019). 
Estudos realizados em dois estados brasileiros concluíram que a incidência de hepatites $B$ e $C$ é maior em adultos em idade produtiva, o que afeta significativamente a economia do país (CRUZ CRB, et al., 2009; GONÇALVES NV, et al., 2019).

O uso da terceira dose contra a hepatite B atingiu $84 \%$ de cobertura global em 2015, o que pode explicar a redução de infecção crônica em crianças abaixo de 5 anos. Entretanto, a transmissão vertical continua sendo a principal fonte de doença hepática crônica quando essas crianças se tornam adultos (OMS, 2017).

Como citado anteriormente, em gestantes a infecção pelo HCV está associada com maior mortalidade, aumento de carcinoma hepatocelular, cirrose e transplante de fígado, além de piores desfechos como diabetes gestacional, pré-eclâmpsia e parto pré-termo (BRASIL, 2020). Essas complicações do HCV associam-se a maior gasto com medicamentos, internações, procedimentos e exames, principalmente por frequentemente a doença ter um diagnóstico tardio (SOUZA JÚNIOR EV, et al., 2019).

Destaca-se a importância da gestação como porta de entrada para os serviços de saúde, com testagens e diagnósticos. Um diagnóstico precoce aumenta as chances de sucesso no tratamento das gestantes, para isso a atenção básica deve ser capaz de identificar, solicitar os exames necessários e realizar encaminhamentos para os serviços de referência (BRASIL, 2012).

\section{Prevenção}

A prevenção das hepatites virais pode ser dividida didaticamente em duas formas: primária e secundária. As medidas primárias (pré-exposição) reduzem o risco de disseminação da doença e as secundárias (pósexposição), a interrupção da progressão da doença em paciente já infectado (BRASIL, 2005). As condutas primárias se baseiam na forma de transmissão de cada vírus, além da imunização adequada conforme calendário vacinal. Para a gestante portadora de hepatite viral, a prevenção secundária é fundamental para evitar a transmissão materno-fetal e possíveis complicações à gestação, o que ressalta a necessidade da pesquisa adequada no pré-natal, uma vez que o manejo é variado a depender do tipo do vírus (BRASIL, 2005).

Em relação a gestantes infectadas pelo HAV e HEV, a contaminação pode ser prevenida por medidas educacionais, de higiene e saneamento básico, reduzindo a contaminação fecal-oral (CHILAKA VN e KONJE JC, 2020). A hepatite $A$ ainda pode ser prevenida antes da exposição com a utilização da vacina específica contra o HAV (BRASIL, 2005). Já para evitar a transmissão perinatal, o RN com mãe infectada pelo HAV deve receber imunoglobulina na dose de $0,02 \mathrm{~mL} / \mathrm{kg}$ e/ou vacina inativada (PESSOA MG e MORAES A, 2018).

Para gestantes infectadas pelo HBV, a abordagem é através da educação sobre transmissão sexual e sanguínea pelo uso compartilhado de agulhas, o controle efetivo de bancos de sangue, além da vacinação disponível no Sistema Único de Saúde (SUS) (BRASIL, 2005). De acordo com a OMS, é mandatório que se determine a carga de DNA viral em gestantes com HBsAg positivo. Quando maior ou igual a $200.000 \mathrm{Ul} / \mathrm{mL}$, estas devem receber Tenofovir profilático da $28^{\text {a }}$ semana até o parto, visando a prevenção da transmissão placentária (WHO, et al., 2020). Recomenda-se ainda que o tratamento continue até 6 a 12 semanas pósparto, para a prevenção de possível progressão e cirrose hepática (CHILAKA VN e KONJE JC, 2020). Já a profilaxia da transmissão perinatal consiste na administração de imunoglobulina (HBlg) e vacina da hepatite B para neonatos de mães infectadas com HBV até 12 horas após o parto. Ao adotar essas orientações, a prevenção perinatal alcança 95\% (PESSOA MG e MORAES A, 2018).

Com referência à hepatite $C$ e $D$, não existe ainda vacina contra esses tipos virais nem profilaxia pósexposição específica (PESSOA MG e MORAES A, 2018; CHILAKA VN e KONJE JC, 2020). Critérios para estimar a transmissão materno-fetal do HCV são a carga viral materna elevada, coinfecção com o HIV e microtransfusões de mãe para feto, como após ruptura de membranas (PESSOA MG e MORAES A, 2018). Entre medidas de prevenção primária do HCV destacam-se triagem em bancos de sangue e de doadores de órgãos. Já a respeito da hepatite $D$, a prevenção é similar a hepatite $B$, visto que o HDV necessita da presença do HBV para contaminação (BRASIL, 2005). 
A amamentação, no caso das hepatites virais, não é contraindicada e deve ser encorajada. Caso haja fissuras mamilares com sangue, a amamentação deve ser interrompida até a completa cicatrização. Faz-se exceção ao HEV, pois ainda não dispomos de dados confiáveis sobre sua transmissão (PESSOA MG e MORAES A, 2018).

\section{Comorbidades e Complicações}

Considerando as complicações das hepatites na gestação, o HAV não causa nenhuma alteração significativa. Contudo, pode estar associado a contração uterina precoce, ruptura de membranas, parto prematuro e peritonite meconial, em especial no $2^{\circ}$ e $3^{\circ}$ trimestres de gestação (PESSOA MG e MORAES A, 2018; SETO MT, et al., 2020). Outro tipo viral associado a comorbidades e a complicações é o HEV. Sua mortalidade ocorre por grave injúria hepática na gestação, pela fisiopatologia de uma resposta imune inadequada, com o envolvimento de função defeituosa de monócitos, macrófagos e citocinas (PÉREZGRACIA MT, et al., 2017). Varia de casos autolimitados a fulminantes, com ruptura das membranas, abortos espontâneos, hemorragias pós parto, eclâmpsia e fetos natimortos (PESSOA MG e MORAES A, 2018).

\section{CONSIDERAÇÕES FINAIS}

As principais repercussões dos tipos de hepatites virais se pautam na alta taxa de transmissibilidade para o feto ou RN, principalmente em casos de mulheres soropositivas para a HBV e HCV, junto com a probabilidade de um parto prematuro ou de outras complicações decorrentes desta infecção. $O$ acesso ao pré-natal em qualquer Unidade Básica de Saúde de qualidade é um dos principais instrumentos no combate às afecções causadas pelas hepatites. Oferta do teste sorológico durante o pré-natal e de vacinação gratuita durante e após a gestação é uma garantia de melhor qualidade de vida para a gestante, feto ou RN. Ademais, - SUS também oferece tratamento e profilaxia para os parceiros sexuais dessas mulheres, diminuindo os riscos de transmissão via sexual. Essas estratégias no combate à doença possibilitam melhores desfechos para essas gestantes infectadas com hepatites virais.

\section{REFERÊNCIAS}

1. BARROS MMO, et al. Hepatitis $B$ and $C$ in pregnant women attended by a prenatal program in an universitary hospital in Rio de Janeiro, Brazil: retrospective study of seroprevalence screening. Arquivos de gastroenterologia, $2018 ; 55$ (3); 267-273.

2. BRASIL. Guia Prático: Infecções no ciclo grávido-puerperal da FEBRASGO. 2016. Disponível em: https://www.febrasgo.org.br/media/k2/attachments/02-INFECCOyES_NO_CICLO_GRAVIDO_PUERPERAL.pdf. Acessado em: 12 de dezembro de 2020.

3. BRASIL. Manual de aconselhamento em hepatites virais do Ministério da Saúde. 2005. Disponível em: https://bvsms.saude.gov.br/bvs/politicas/hepatites_aconselhamento.pdf. Acessado em: 27 de dezembro de 2020.

4. BRASIL. Manual de Atenção ao Pré-natal de Baixo Risco do Ministério da Saúde. 2012. Disponível em: http://bvsms.saude.gov.br/bvs/publicacoes/atencao_pre_natal_baixo_risco.pdf. Acessado em: 22 de dezembro de 2020.

5. BRASIL. Manual Técnico para o Diagnóstico das Hepatites Virais do Ministério da Saúde. 2018. Disponível em: http://www.aids.gov.br/pt-br/pub/2015/manual-tecnico-para-o-diagnostico-das-hepatites-virais . Acessado em: 9 de janeiro de 2021.

6. BRASIL. Ministério da Saúde. Secretaria de Vigilância em Saúde. Hepatites Virais: o Brasil está atento. 2008. Disponível em: https://bvsms.saude.gov.br/bvs/publicacoes/hepatites_virais_brasil_atento_3ed.pdf. Acessado em: 28 de novembro de 2020.

7. BRASIL. Testagem universal para hepatite viral C em gestantes no pré-natal. 2020. Disponível em: http://conitec.gov.br/images/Consultas/Relatorios/2020/Relatorio_TestagemUniversal_HepatiteC_Gestantes_CP_19 2020.pdf. Acesso em: 9 de dezembro de 2020.

8. CHILAKA VN, KONJE, JC. Viral Hepatitis in pregnancy. European Journal of Obstetrics \& Gynecology and Reproductive Biology, 2020; 256; 287-296.

9. CONCEICAO JS, et al . Conhecimento dos obstetras sobre a transmissão vertical da hepatite B. Arq. Gastroenterol., 2009; $46(1) ; 57-61$.

10. CRUZ CR, et al. Comparação do perfil epidemiológico das hepatites B e C em um serviço público de São Paulo. Arq. Gastroenterol., 2009; 46(3); 225-229.

11. FERNANDES CNS, et al. Prevalência de soropositividade para Hepatite B e C em gestantes. Rev. esc. enferm. 2014; 48(1).

12. FERREIRA CT, SILVEIRA TR. Hepatites virais: aspectos da epidemiologia e da prevenção. Rev. bras. epidemiol., $2004 ; 7(4) ; 473-487$. 
13. GONÇALVES NV, et al. Análise Espacial e Epidemiológica de Hepatites B e C e Índice de Desenvolvimento Humano Municipal, no Estado do Pará. Hygeia - Revista Brasileira de Geografia Médica e da Saúde, 2019; $15(31) ; 29$ - 42.

14. IBAS JLC, et al. Hepatite C: uma abordagem educacional na promoção de saúde. Revista Saúde e Desenvolvimento, 2018; 12(10); 5-17.

15. JAISWAL SPB, et al. Viral hepatitis during pregnancy. International Journal of Gynecology \& Obstetrics, 2001; 72(2); 103-108.

16. ŁAPIńSKI TW, et al. Effect of hepatitis B virus (HBV) infection on the course of pregnancy and newborns' health status. Clinical And Experimental Hepatology, 2015; 3; 112-116.

17. MACHADO FILHO AC, et al. Prevalência de infecção por HIV, HTLV, VHB e de sífilis e clamídia em gestantes numa unidade de saúde terciária na Amazônia ocidental brasileira. Rev. Bras. Ginecol. Obstet., 2010; 32(4); 176-183.

18. MANSOUR W, et al. Prevalência, fatores de risco e epidemiologia molecular da hepatite $B$ e vírus da hepatite delta em mulheres grávidas e em pacientes na Mauritânia. J Med Virol, 2012; 84(8); 1186 - 1198.

19. PARANÁ R, et al. Hepatitis D Virus. Human Virology In Latin America, 2017; 361-374.

20. PEIXOTO MF, et al. Vertical transmission of hepatitis $C$ virus in a hospital in southern Brazil. Arq Gastroenterologia. 2004; 41(2); 84-87.

21. PÉREZ-GRACIA MT, et al. Hepatitis E and pregnancy: current state. Reviews in medical virology, 2017; 27(3); e1929.

22. PESSOA MG, MORAES A. Hepatites virais na gravidez. Protocolo Febrasgo - Obstetrícia, Comissão Nacional Especializada em Doenças Infecto-Contagiosas, 2018; 62; 4-16.

23. PIAZZA MJ, et al. Hepatites virais e gestação. Diagn Tratamento, 2010; 15(1); $12-8$.

24. RAC MWF, SHEFFIELD JS. Prevention and Management of Viral Hepatitis in Pregnancy. Obstetrics And Gynecology Clinics Of North America, 2014; 41(4); 573-592.

25. SETO MT, et al. Management of Viral Hepatitis A, C, D and E in pregnancy. Best Practice \& Research Clinical Obstetrics \& Gynaecology, 2020; 68:44-53.

26. SOUZA JÚNIOR EV, et al. Gastos públicos com hospitalizações devido às hepatites virais. Rev. enferm. UFPE on line, 2019; 1-7.

27. TAVARES MV, et al. VACINAS E GRAVIDEZ. Acta Medica Portuguesa, 2011; 24(S4); 1063-1068.

28. VIANA DR, et al. Hepatite B e C: diagnóstico e tratamento. Revista de Patologia do Tocantins, $2017 ; 4$ (3); $73-$ 79.

29. VIELLAS E, et al. Assistência pré-natal no Brasil. Cad. Saúde Pública, 2014; S85-S100.

30. WHO. WORLD HEALTH ORGANIZATION. Global hepatitis report, 2017. 2017. Disponível em: http://apps.who.int/iris/bitstream/10665/255016/1/9789241565455-eng.pdf?ua=1. Acesso em: 20 de dezembro de 2020.

31. WHO. WORLD HEALTH ORGANIZATION. Prevention of mother-to-child transmission of hepatitis B virus: guidelines on antiviral prophylaxis in pregnancy. 2020. Disponível em: https://apps.who.int/iris/rest/bitstreams/1288482/retrieve. Acesso em: 10 de janeiro de 2021. 